\title{
Prevalence and risk factors of post partum depression in a sample of women in Basrah
}

Accepted: 26/8/2014

\author{
Shukrya K. Khalaf *
}

\section{Abstract}

Background and objective: Post partum depression is considered an important public health concern worldwide with its negative impact on mothers and children. The aim of this study was to determine the prevalence and risk factors of post partum depression among women in Basrah.

Methods: Data were collected by interviewing women 8-12 weeks post partum using a questionnaire including information on socio-demographic and prenatal, natal and postnatal medical history. Postpartum depression was assessed using an Edinburgh Postnatal Depression Scale.

Results: A total of 302 women were included in the study. The prevalence of postnatal depressive symptoms was $31.5 \%$. The results showed no significant relationships between depression symptoms and education, occupation, monthly income and parity, while several obstetric and psychosocial variables were significantly associated with postnatal depression. On multiple regression analysis, history of depressive symptoms, anaemia during pregnancy, exposure to violence and relationship with mother or daughter in law remained significant factors $(P<0.001)$

Conclusion: A substantial number of women in Basrah showed postpartum depression. Further research is required to affirm these determinations.

Keywords: Post-partum depression, Prevalence, Risk factors, Basrah.

\section{Introduction}

Post partum depression (PPD) is a crucial public health concern in forward-looking communities $^{1,2}$ with a quick health effect on the woman and her assurance as a mother and at later on her infants' emotional, cognitive and physical development due to deficient maternal infant interact. ${ }^{3,4}$ PPD is considered the most usual medical ramification of childbirth, touching $10-15 \%$ of women worldwide. ${ }^{5-7}$ The prevalence is different according to population tried and screening instrument put-upon (screening standardized diagnostic tool), the point in the time applied, dissimilar cut off points of the same tool and other ethnic and geographical issues. ${ }^{8}$ The diagnostic and statistical manual of mental disorders define PPD as a major depressive episode that take place within four weeks after delivery and this risk may extend for one year. ${ }^{9}$ The symptoms of PPD are tearfulness, dependency, and feeling of guilt, insomnia, fatigue, and appetite change. ${ }^{10}$ The imminent depressive danger was described during the first 3-4 months post partum in a lot of cases. ${ }^{11}$ So screening of PPD is exceedingly significant and should be carried out on regular bases after six weeks postnatal. The exact causes of post partum depression remain obscure, but at the same time it is likely that several constituents, including psychological, biological, and social are tangled and so considered as multifactorial aetiology. ${ }^{12}$ The most coherently risk factors are an early history of depression, history of psychiatric illness, and depression during pregnancy, ${ }^{13}$ experience of stressful life events during pregnancy and few months before. ${ }^{11}$ Other factors

* Department of Community Medicine, College of Medicine, Basrah University, Basrah, Iraq. 
considered as important in low-income countries like lack of perceived social support and family disruption. ${ }^{14}$ A review of many studies showed that the prevalence rate of PPD in high-income countries was lower than the prevalence of PPD in low-middle income countries. ${ }^{12}$ Some risk factors are exclusively seen in eastern and Arabic societies, such as dissatisfaction with having female child, increased parity and poor relationship with the husband and or relatives. ${ }^{15}$ Nutritional factors have been associated with PPD, including fatty acid zinc and iron. ${ }^{5}$ Iron is the predominant food inadequacy in all-childbearing women worldwide and several studies showed that anaemia due to iron deficiency was associated with PPD symptoms. ${ }^{6}$ Apart from one study done in Kurdistan region in north Iraq, ${ }^{16}$ from literature search, no study reporting the prevalence and risk factors of PPD in Basrah population has been conducted. So this study was conducted with the aim of determining the prevalence of PPD and its associated risk factors among Basrah women.

\section{Methods}

A cross-sectional study was conducted over a period of six weeks from March $15^{\text {th }}$, to May $2^{\text {nd }}, 2014$. A list of primary health care $(\mathrm{PHC})$ centers in Basrah city was obtained from Basrah General Health Directorate. A total of $14 \mathrm{PHC}$ centres were chosen by systematic random method (every third of the list). The sample size was calculated according to the following equation: ${ }^{17}$

$$
\mathrm{n}=\frac{Z^{2} \mathrm{P}(1-\mathrm{P})}{\mathrm{d}^{2}}
$$

Where $(n)$ is the sample size, $Z=Z$ statistic for a level of confidence. For the level of confidence of $95 \%$, which is conventional, $Z$ value is 1.96. $\mathrm{P}=$ expected prevalence or prevalence from previous studies, which was $28.4 \%$ according to Ahmed et al study. ${ }^{16} \mathrm{~d}=$ precision or margin of error allowed. In this study a degree of precision of 0.05 was used. The sample size was calculated to be 313. Taking in consideration a non-response rate of $10 \%$, the sample size was extended to 344 . The sample size was distributed proportionally between the selected PHC centres. The participants were women chosen by simple random sampling from those who were in the post partum period (8-12 weeks) attending the chosen $\mathrm{PHC}$ centres in Basrah City for vaccination of their babies. Exclusion criteria included the illiterate women and those who were well known to have any psychiatric illness. Data were collected by interviewing the participants according to a special questionnaire designed for the purpose of the study. The questionnaire consisted of two parts. The first part covered the socio-demographic variables, which included age, education, occupation, parity and family income. The second part checked obstetric history variables and past psychiatric history. The Arabic version of the Edinburgh Postnatal Depression Scale (EPDS) was used to assess the postnatal depression symptoms. The EDPS is a ten item self report scale validated and widely used to screen for PPD in community samples. ${ }^{18}$ The EDPS is a 10-item self-rating scale. Each item is scored $0-3$ and the maximum total score is 30 . Seven of its items are reverse-scored. The scale rates the strength of depressive symptoms present within the formers seven days. Participants who collect ten scores or higher on the EPDS were considered as potential PPD cases and those who collect less than ten were considered normal. An Informed verbal consent was obtained and the participants were briefed about the study and encouraged to participate. The Ethical Committee of the College of Medicine approved the research proposal and another endorsement from the Directorate of Health in Basrah was also obtained. Confidentiality was assured through namelessness of the questionnaire. The collected information was kept secret and used only for research purposes. Organization was made for 
adequate referral of participants discovered at risk of depression. Data were coded, and analysed using the statistical package for the social sciences (version 20.0). Descriptive statistics, including mean and standard deviation (SD) and frequencies were used for summarizing the data and outcome variables. Chi-squared test and Odds ratios (OR) with 95\% confidence intervals $(\mathrm{Cl})$ were used to quantify the risk factors. Binary logistic regression was done taking depression as dichotomous variable with the referent category being not having PPDS to identify the independent risk factors associated with PPD. P $<0.05$ was considered statistically significant. ${ }^{19}$

\section{Results}

Of 344 targeted women, 302 participated in the study, representing a response rate of $87.7 \%$. The prevalence of PPD was $31.5 \%$. The mean ( \pm SD) age of the participants was $26.68( \pm 5.935)$ years (range 16-40 years). Table 1 shows the basic demographic characteristics of the participants and their association with PPD. Of the total participants, 147 (48.6\%) women were aged 25 years and below with a depression rate of $38.8 \%$, whereas 26 $(8.7 \%)$ women were aged more than 35 years with a depression rate of $15.4 \%$ with a significant difference $(P=0.016)$. Women who were housewives constituted $87.1 \%$ of the study population with PPD rate of $31.9 \%$, while those who were employed constituted $12.9 \%$ of the study population with a prevalence rate of PPD $28.2 \%$ without a significant association between occupation and PPD. Women with university education were 74 (24.5\%) and the prevalence of depression among them was $29.7 \%$ compared to $32.9 \%$ among women with primary/intermediate education without significant difference. Family monthly income and parity showed no significant association with PPD.

Table 1: Socio-demographic characteristics and heir association with PPD.

\begin{tabular}{|c|c|c|c|}
\hline Variables & $\begin{array}{l}\text { PPD } \\
\text { No. (\%) }\end{array}$ & $\begin{array}{l}\text { No PPD } \\
\text { No. (\%) }\end{array}$ & $\mathbf{p}$ \\
\hline \multicolumn{4}{|l|}{ Age (years } \\
\hline$\leq 25$ & $57(38.8)$ & $90(61.2)$ & 0.016 \\
\hline $26-35$ & $34(26.4)$ & $95(73.6)$ & \\
\hline$>35$ & $4(15.4)$ & $22(84.6)$ & \\
\hline \multicolumn{4}{|l|}{ Education } \\
\hline Read \&right & $8(29.6)$ & $19(70.4)$ & \\
\hline Primary/intermediate & $53(32.9)$ & $108(67.1)$ & 0.952 \\
\hline Secondary & $12(30.0)$ & $28(70.0)$ & \\
\hline University & $22(29.7)$ & $52(70.3)$ & \\
\hline \multicolumn{4}{|l|}{ Occupation } \\
\hline Housewife & $84(31.9)$ & $179(68.1)$ & \\
\hline Employed (governmental and non- governmental) & $11(28.2)$ & $28(71.8)$ & 0.639 \\
\hline \multicolumn{4}{|l|}{ Family monthly income } \\
\hline$<500000$ ID & $50(30.3)$ & $115(69.7)$ & \\
\hline 500000ID-million ID & $32(31.1)$ & $71(68.9)$ & 0.659 \\
\hline >1million ID & $13(28.3)$ & $21(71.7)$ & \\
\hline \multicolumn{4}{|l|}{ Parity } \\
\hline Para 1 & $30(35.7)$ & $54(64.3)$ & \\
\hline Para 2-3 & $37(31.4)$ & $81(68.6)$ & 0.532 \\
\hline Para $\geq 4$ & $28(28.0)$ & $72(72.0)$ & \\
\hline
\end{tabular}


Table 2 presents the psychosocial and obstetric characteristics of the study population and their association with PPD. Of the studied women, 127 (42.1\%) had anaemia, of whom $57.5 \%$ showed PPD with a highly significant association $(P<0.001)$. Eighty-eight $(29.1 \%)$ of the studied women reported past history of depression, of whom $62(70.5 \%)$ showed PPD with a highly significant association. association was noted between PPD and pregnancy period, mode of delivery, sex of the last baby, non-preferred sex of the present baby, and planning of last pregnancy. Similarly, poor relationship with mother or daughter in law and a past history of exposure to violence was significantly associated with PPD. No significant

Table 2: Association between PPD and obstetrics and psychosocial characteristics of the participants.

\begin{tabular}{|c|c|c|c|}
\hline Variables & $\begin{array}{l}\text { PPD } \\
\text { No. (\%) }\end{array}$ & $\begin{array}{l}\text { No PPD } \\
\text { No. (\%) }\end{array}$ & $\mathbf{P}$ \\
\hline $\begin{array}{l}\text { Anaemia during pregnancy }(<11 \mathrm{gm} / \mathrm{dl}) \\
\text { Yes } \\
\text { No }\end{array}$ & $\begin{array}{l}73(57.5) \\
22(12.6)\end{array}$ & $\begin{array}{l}54(42.5) \\
153(87.4)\end{array}$ & $<0.001$ \\
\hline $\begin{array}{l}\text { Pregnancy period } \\
\text { Full term ( } \geq 37 \text { weeks gestation) } \\
\text { Premature (<37 weeks gestation) }\end{array}$ & $\begin{array}{l}88(31.4) \\
7(31.8)\end{array}$ & $\begin{array}{l}192(68.6) \\
15(68.2)\end{array}$ & 0.970 \\
\hline $\begin{array}{l}\text { Mode of delivery } \\
\text { Vaginal } \\
\text { Caesarean section }\end{array}$ & $\begin{array}{l}71(32.1) \\
24(29.6)\end{array}$ & $\begin{array}{l}150(67.9) \\
57(70.4)\end{array}$ & 0.679 \\
\hline $\begin{array}{l}\text { Sex of the last baby } \\
\text { Male } \\
\text { Female }\end{array}$ & $\begin{array}{l}50(31.4) \\
45(31.5)\end{array}$ & $\begin{array}{l}109(68.6) \\
98(68.5)\end{array}$ & 0.997 \\
\hline $\begin{array}{l}\text { Past history of depression } \\
\text { Yes } \\
\text { No }\end{array}$ & $\begin{array}{l}62(70.5) \\
33(15.4)\end{array}$ & $\begin{array}{l}26(29.5) \\
181(84.6)\end{array}$ & $<0.001$ \\
\hline $\begin{array}{l}\text { Psychological disease in the family } \\
\text { Yes } \\
\text { No }\end{array}$ & $\begin{array}{l}18(51.4) \\
77(28.8)\end{array}$ & $\begin{array}{l}17(48.6) \\
190(71.2)\end{array}$ & 0.007 \\
\hline $\begin{array}{l}\text { Exposure to violence } \\
\text { Yes } \\
\text { No }\end{array}$ & $\begin{array}{l}51(58.0) \\
44(20.6)\end{array}$ & $\begin{array}{l}37(42.0) \\
170(79.4)\end{array}$ & $<0.001$ \\
\hline $\begin{array}{l}\text { Sex of present baby not preferred } \\
\text { Yes } \\
\text { No }\end{array}$ & $\begin{array}{l}17(34.7) \\
78(30.8)\end{array}$ & $\begin{array}{l}32(65.3) \\
175(69.1)\end{array}$ & 0.594 \\
\hline $\begin{array}{l}\text { Relationship with mother } \\
\text { Or daughter-in- law } \\
\text { Good } \\
\text { Bad }\end{array}$ & $\begin{array}{l}48(21.4) \\
47(60.3)\end{array}$ & $\begin{array}{l}176(78.6) \\
31(39.7)\end{array}$ & $<0.001$ \\
\hline $\begin{array}{l}\text { Planning of last pregnancy } \\
\text { Yes } \\
\text { No }\end{array}$ & $\begin{array}{l}56(28.4) \\
39(37.1)\end{array}$ & $\begin{array}{l}141(71.6) \\
66(62.9)\end{array}$ & 0.120 \\
\hline
\end{tabular}


To examine the independent association of the studied risk factors and PPD, a binary logistic regression analysis was performed. The variables, which showed a significant independent association were; past history of depression, anaemia during pregnancy, history of exposure to violence, and poor relationship with mother or daughter in law (Table 3).

\section{Discussion}

The prevalence of PPD in this study was $31.5 \%$, which is somewhat higher than worldwide rate of PPD $(10-15 \%) .^{5-7}$ This is also higher than that reported in Kurdistan, Iraq $^{16}$ and some Arab and surrounding countries such as Lebanon $(21 \%)^{3}$ Turkey $(25.6 \%),{ }^{20}$ and Iran $(20 \%){ }^{4}$ However, it is slightly lower than that reported in some Arab countries such as Bahrain $(37.1 \%){ }^{21}$ and Saudi Arabia (33.2\%). ${ }^{5}$ Such variation in prevalence is not astonishing as a review study reported a very broad scope of prevalence due to varieties of socio-cultural factors, ${ }^{22}$ or may be due to variance of the tools used for measurement of depression and ethnic issues. ${ }^{23}$ Education, occupation and monthly incomes were not significantly associated with PPD. This finding is in accordance with other studies. ${ }^{5,15}$ Younger age (< 25 years) was significantly associated with high risk of PPD, which is in agreement with studies that done in Saudi
Arabia $^{5}$ and Costa Rica and Chile, ${ }^{24}$ which declared that young age is a risk factor for PPD. However, such association disappeared on multivariate analysis that may be explained by confounding by other factors such as social support which was clear in a study that done in China and showed that younger mothers are more liable to get depression but such depression decreases when there is a social support ${ }^{25}$ and it is well known that social ties and support are high in our society. With regard to the sex of the child, no significant association was discovered between sex of the child and risk of PPD, which agrees with studies done in Saudi Arabia ${ }^{5}$ and Sweden, ${ }^{26}$ but it is inconsistent with other studies done in Turkey, ${ }^{20}$ China, ${ }^{27}$ and Egypt $^{28}$ which observed significant association between gender of the baby and the risk of PPD. In this study, the mode of delivery had no relation with risk of PPD which agrees with that reported by other studies in Turkey ${ }^{2}$ and Iran $^{29,30}$ who stated that delivering vaginally or by caesarean section had no effect on the PPD. In this study, previous history of depression was significantly associated with PPD and this result is in conformity with that reported by other researches. ${ }^{3,11,22,23}$ The other risk factor that was significantly associated with PPD symptoms in this study is anaemia during

Table 3: Logistic regression analyses of PPD and related factors.

\begin{tabular}{lll}
\hline Variables & (OR) 95\% C.I & p-value \\
\hline $\begin{array}{l}\text { Past history of depression } \\
\text { Negative }\end{array}$ & 1 & \\
Positive & $5.41(2.62-11.23)$ & $<0.001$ \\
$\begin{array}{l}\text { Anaemia during pregnancy } \\
\text { Negative }\end{array}$ & 1 & \\
$\begin{array}{l}\text { Positive } \\
\text { Expose to violence }\end{array}$ & $3.44(1.70-6.76)$ & 0.001 \\
$\begin{array}{l}\text { Negative } \\
\text { Positive }\end{array}$ & 1 & \\
$\begin{array}{l}\text { Relationship with mother and daughter- in -law } \\
\text { Good }\end{array}$ & $3.44(1.75-6.77)$ & 0.001 \\
Bad & 1 & \\
\hline
\end{tabular}


pregnancy, ${ }^{31}$ which is in consistence with other studies done in Saudi Arabia ${ }^{5}$ and $\operatorname{Iran}^{6}$ which showed that identification and management of anaemia during pregnancy would decrease the risk of PPD. The decreased level of haemoglobin can induce fainting, helplessness, prickling of the extremities and negative consequences on self-reported character of life, contributing to depressive symptoms in the women. ${ }^{32}$ A significant relationship between exposure to violence and the symptoms of post partum depression had been found in this study, a result which agrees with that of a study done in Chile. ${ }^{33}$ The relationship with mother or daughter in law was found to affect PPD significantly; this result is consistent with the finding of a study done in China. ${ }^{25} \mathrm{~A}$ few limitations must be addressed in this study. This was a cross-sectional study based on observational information, which does not certify causing. Furthermore, the only screening tool used for estimation of depression in this research was the EPD scale but further diagnostic tests for ratification are recommended.

\section{Conclusion}

The prevalence of PPD in this study appeared relatively high as compared with other studies carried on in the area. Substantial endeavour and resourcefulness would be a requisite to put on an intervention program. The research's findings call for another study that is required by the comprehension of appropriate diagnostic instrument.

\section{Conflicts of interest}

The author reports no conflicts of interest.

\section{References}

1. McCoy SJ, Beal JM, Shipman SB, Payton ME, Watson GH. Risk factors for postpartum depression: a retrospective investigation at 4-weeks postnatal and a review of the literature. J Am Osteopath Assoc 2006; 106(4):193-8.

2. Goker A, Yanikkerem E, Demet MM, Dikayak S, Yildirim Y, Koyuncu FM. Postpartum depression: is mode of delivery a risk factor? Obstet Gynecol 2012; 2012: 616759.
3. Chaaya M, Campbell OM, El Kak F, Shaar D, Harb H, KaddourA. Postpartum depression: prevalenceand determinants in Lebanon. Arch Womens Ment Health 2002; 5(2):65-72.

4. Najafi K, Zarrabi H, Avakh MF, Nazifi F. Prevalence of depression in a group of women delivering at a hospital in Rasht City, Iran. JPPS 2007; 4(2):100-07.

5. Alharbi AA, Abdulghani HM. Risk factors associated with postpartum depression in the Saudi population. Neuropsychiatric Dis Treat 2014; 10:311-6.

6. Goshtasebi A, Alizadeh M, Gandevani SB. Association between maternal anaemia and postpartum depression in an urban sample of pregnant women in Iran. J Health Popul Nutr 2013; 31(3):398-402.

7. Fisher J, Cabral de Mello M, Patel V, Rahman A, Tran T, Holton S, Holmes W. Prevalence and determinants of common perinatal mental disorders in women in low- and Lower-middleincome countries: a systematic review. Bull World Health Organ 2012; 90(2):139G-49G.

8. Taherifard $P$, Delpisheh A, Shirali R, Afkhamzadeh A, Veisani Y. Socioeconomic, psychiatric and materiality determinants and risk of postpartum depression in border city of llam, Western Iran. Depress Res Treat.2013; 2013: 653471.

9. Sit DK, Wisner KL. Identification of postpartum depression. Clin Obstet Gynecol 2009; 52(3): 456-68.

10. Veisani Y, Delpisheh A, Sayehmiri K, Rezaeian S. Trends of postpartum depression in Iran: a systematic review and meta-analysis. Depress Res Treat 2013; 2013:291029.

11. Kheirabadi GR, Maracy MR, Barekatain M, Salehi M, Sadri GH, Kelishadi M, Cassy P. Risk factors of post partum depression in rural areas of Isfahan Province, Iran. Arch Iran Med. 2009; 12 (5):461-7.

12. Mathisen SE, Glavin K, Lien L, Lagerløv P. Prevalence and risk factors for postpartum depressive symptoms in Argentina: a crosssectional study. Int J Womens Health.2013; (5):787-93.

13. Andrews-Fike C. A Review of postpartum depression. Prim Care Companion $\mathrm{J}$ Clin Psychiatry.1999; 1(1): 9-14.

14. Husain N, Bevc I, Husain M, Chaudhry IB, Atif N, Rahman A. Prevalence and social correlates of postnatal depression in a low-income country. Arch Womens Ment Health.2006; 9(4): 197-202.

15. Gürel $\mathrm{Sa}$, Gürel $\mathrm{H}$. The evaluation of determinants of early postpartum low mood: the Importance of parity and inter-pregnancy interval. Eur $\mathrm{J}$ Obstet Gynecol Reprod Biol. 2000; 91(1): 21-4.

16. Ahmed HM, Alalaf SK, Al-Tawil NG. Screening for postpartum depression using Kurdish Version of Edinburgh postnatal depression scale. Arch Gynecol Obstet. 2012; 285(5): 1249-55. 
17. Naing L, Winn T, Rusli BN. Practical Issues in Calculating the Sample Size for Prevalence Studies. Archives of Orofacial Sciences 2006; 1: 9-14

18. Ghubash R, Abou-Saleh MT, Daradkeh TK, The validity of the Arabic Edinburgh Postnatal Depression Scale. Soc Psychiatry Psychiatr Epidemiol. 1997; 32(8): 474-6.

19. Harris M, Taylor G (Eds). Medical statistics made easy, Springer-Verlag New York Inc., New York, 2004, pp 24-7.

20. Dindar I, Erdogan S. Screening of Turkish women for postpartum depression within the; first postpartum year: the risk profile of a community sample. Public Health Nurs.2007; 24(2): 176-83.

21. Al Dallal FH, Grant IN. Postnatal depression among Bahraini women: prevalence of symptoms and psychosocial risk factors. East Mediterr Health J 2012; 18(5): 439-45.

20. Halbreich U, Karkun S. Cross-cultural and social diversity of prevalence of postpartum depression and depressive symptoms. J Affect Disord2006; 91(2-3): 97-111.

23. Ramasubramaniam S, Madhavanprabhakaran GM, Lakshmi R, Raman S. Prevalence of postnatal depression among Arab women: a narrative review. Journal of Research In Nursing and Midwifery (JRNM). 2014; 3(1) : 1-13.

24. Wolf AW, De Andraca I, Lozoff B. Maternal depression in three Latin American samples. Soc Psychiatry Psychiatr Epidemiol. 2002; 37(4): 169-76.

25. Xie RH, He G, Koszycki D, Walker M, Wen SW. Prenatal Social Support, Postnatal Social Support, and Postpartum Depression. Ann Epidemiol. 2009;19(9): 637-43.

26. Sylvén SM, Papadopoulos FC, Mpazakidis V, Ekselius L, Sundström-Poromaal ,Skalkidou A. Newborn gender as a predictor of postpartum mood disturbances in sample of Swedish women. Arch Womens Ment Health2011; 14(3): 195-201.

27.Deng AW, Xiong RB, Jiang TT, Luo YP, Chen WZ. Prevalence and risk factors of postpartum Depression in a population-based sample of women in Tangxia Community, Guangzhou. Asian Pac J Trop Med. 2014; 7(3): 244-9.

28. Hassanein IM, Fathalla MM, Abdel Rahim T. The role of new born gender in postpartum depressive symptoms among women in Upper Egypt. Int J Gynaecol Obstet. 2014; 125(2): 138-40.

29. Sadat Z, Kafaei AM, Masoudi AN, Abbaszadeh $F$, Karimian Z, Taherian A.Effect of mode of delivery on postpartum depression in Iranian women. J Obstet Gynaecol Res. 2014; 40(1): 172-7.

30. Azar IAS, Hashemi Z, Forghani F. Postpartum depression and its correlates among Women Living in Zabol (Iran). Iran J Psychiatry.2006; 1: 140-7.
31. Haemoglobin concentration for the diagnosis of anaemia and assessment of severity. http://www.int world health organization2011.

32. Beard JL, Hendricks MK, Perez EM, Murray-Kolb LE, Berg A, Vernon-Feagans L, et al. Maternal iron deficiency anaemia affects postpartum emotions and cognition. J Nutr 2005; 135(2): 267-72.

33. Quelopana AM. Violence against women and postpartum depression: the experience of Chilean women. Women Health 2012;52(5):437-53. 